\title{
COMUNICACIÓN
}

\section{Estimación de la prevalencia de equinococosis canina en la XII Región, Chile, 2002}

\author{
FRANCISCO ALVAREZ*, RAFAEL TAMAYO** y SANTIAGO ERNST**

\begin{abstract}
ESTIMATION OF THE CANINE ECHINOCOCCOSIS PREVALENCE IN THE XII REGION, CHILE, 2002
\end{abstract}

The objetive of this study was to estimate the echinococcosis prevalence in dogs in the XII Region. In the three Provinces in which the Hydatidosis Control Proyect is developed a random sample of 228 dogs was taken. In the field the arecoline test was used and, addicionally, a questionary was applied to the dog owners. The results of the arecoline test showed four positive dogs $(1,8 \%)$, three in the Ultima. Esperanza Province and one in Tierra del Fuego. It can be concluded that the prevalence of canine echinococcosis in the XII Region remained at a low level since 1982. It is important to increase the efforts and adopt new strategies in order to erradicate the disease from the Region.

Key words: Canine echinococcosis, prevalence, arecoline test, Chile.

\section{INTRODUCCIÓN}

La equinococosis es una enfermedad parasitaria y zoonótica de distribución mundial ${ }^{1}$ el agente etiológico descrito en Chile es el Echinococcus granulosus, siendo el perro el hospedador definitivo de mayor importancia epidemiológica ${ }^{2}$. Esta enfermedad tiene una mayor prevalencia en áreas donde la ganadería es la actividad más relevante ${ }^{3-4}$.

La hidatidosis es una patología causada por el estado larval, el metacéstodo, de las especies del género Echinococcus ${ }^{5}$; el hombre y los animales domésticos desarrollan la forma quística de la enfermedad. Durante el año 2001 se diagnosticaron en Chile 189.905 bovinos y 17.297 ovinos afectados con esta patología ${ }^{6}$, siendo la segunda causal de decomisos en mataderos ${ }^{7}$; ese mismo año se notificaron 325 casos de hidatidosis humana ${ }^{8}$.
La prueba de "arecolina" es la técnica utilizada tradicionalmente para determinar la prevalencia de equinococosis. Este método se basa en el empleo de bromhidrato de arecolina, alcaloide derivado de la nuez de areca, con acción parasimpaticomimética ${ }^{9}$, que produce, en el individuo tratado, la evacuación del contenido intestinal ${ }^{10}$. Actúa sobre la musculatura lisa del parásito, provocándole parálisis y causando su desprendimiento de la mucosa entérica ${ }^{11}$. Se describe una alta sensibilidad, cercana al $100 \%$, con valores predictivos positivos altos, a través de todo el rango de posibles prevalencias, mientras que el valor predictivo negativo bordea el $68 \%{ }^{12}$. La especificidad depende de la respuesta efectiva del perro a la administración de bromhidrato de arecolina, logrando la evacuación intestinal (10 a $25 \%$ de los perros no reaccionan a la droga), y de la técnica en la lectura de la muestra ${ }^{6-13}$.

\footnotetext{
* Servicio Agrícola y Ganadero, Sector Última Esperanza.

** Instituto de Medicina Preventiva Veterinaria, Facultad de Ciencias Veterinarias, Universidad Austral de Chile.
} 
Desde el año 1979 el Servicio Agrícola y Ganadero (SAG) impulsa en el sector rural, con financiamiento propio y del Gobierno Regional, un proyecto de Control de la Hidatidosis en la XII Región de Magallanes y Antártica Chilena ${ }^{14}$, con el objetivo de diminuir la prevalencia de la enfermedad en especies susceptibles de importancia económica, logrando al mismo tiempo una menor morbilidad humana ${ }^{15}$. Luego de más de veinte años desarrollando actividades de control, se ha logrado disminuir la prevalencia de hidatidosis ovina de $60,0 \%$ a $3,7 \%$, y de equinococosis canina de $71,4 \%$ a $0,54 \%{ }^{16}$.

El objetivo del presente trabajo es estimar la prevalencia de equinococosis canina en la XII Región, Chile y describir su distribución según variables epidemiológicas descriptivas dependientes de los individuos afectados y área geográfica.

\section{MATERIAL Y MÉTODOS}

El muestreo en terreno se realizó entre Agosto y Diciembre del año 2002, utilizándose como método diagnóstico la prueba de arecolina ${ }^{17}$, con lectura inmediata en fondo oscuro. Paralelamente se aplicó una encuesta sobre probables factores de riesgo a cada uno de los propietarios de perros muestreados, registrándose en una planilla de campo las siguientes variables : $\mathrm{N}^{\circ}$ de registro, nombre, edad aproximada y labor que realiza el perro (mascota, trabaja con ovinos, bovinos o mixto, es decir ovinos y bovinos); nombre del propietario; nombre del predio; provincia y actividad ganadera predial (ovina, bovina o mixta).

El tamaño muestral se estimó de acuerdo a la fórmula $\mathrm{n}=\left[1-(1-\mathrm{NC})^{1 / \mathrm{d}}\right] \mathrm{x}[\mathrm{N}-(\mathrm{d}-1) / 2]$, incluida en programa Win episcope 2.0. Se utilizó una prevalencia crítica (d) de $1,5 \%$ y un nivel de confianza (NC) de $95 \%$. Se calculó una muestra (n) igual a 196 perros, a la cual se le incorporaron 32 individuos por posible impedimento de realizar el examen. Este diseño permite detectar al menos un animal positivo, si la verdadera prevalencia es igual o superior a $1,5 \%$, con un $95 \%$ de confianza ${ }^{18}$. En el caso de encontrar más de un animal positivo se calcula la prevalencia puntual como un estimador de la verdadera prevalencia poblacional.

El marco muestral estuvo constituido por los caninos inscritos en el Proyecto de Control de la Hidatidosis, año 2001 ( $\mathrm{N}=6.611)$. Se utilizó un procedimiento del muestreo estratificado, asignando proporcionalmente a cada una de las tres provincias en donde se desarrolló el trabajo, el número de perros a muestrear, de acuerdo al aporte porcentual de cada una de ellas a la población total de perros. Esto significó obtener 103 (44,6\%) muestras de la Provincia Última Esperanza, 85 $(36,8 \%)$ de la Provincia de Tierra del Fuego y 40 $(17,3 \%)$ de la Provincia de Magallanes.

Finalmente la información se ingresó a una planilla computacional, luego de lo cual se realizó un estudio epidemiológico descriptivo consistente en el cálculo de la prevalencia de equinococosis individual y predial y su distribución según variables de edad, nombre del propietario, nombre del predio, provincia y actividad ganadera predial.

\section{RESULTADOS Y DISCUSIÓN}

Existe una diferencia en las cantidades absolutas y porcentuales del número de muestras estudiadas en relación al muestreo estadístico realizado en la XII Región en 1982, el que tuvo un $\mathrm{n}=1.169^{19}$, probablemente debido al cambio en los parámetros para determinar el tamaño de muestra (prevalencia y universo canino).

Se estimó en un 1,8\% (4/228) de prevalencia de equinococosis canina a nivel regional, la que se mantiene a niveles bajos desde 1982, aumentando levemente en los últimos años (0,31\%, año 2000; 0,43\%, año 2001), esta diferencia se debería al diseño muestral empleado, que en los últimos cuatro años tenía como unidad muestral al propietario*. Por otro lado, la prevalencia obtenida es equivalente a las logradas en las Provincias Argentinas de Río Negro ${ }^{20}$ y Tierra del Fuego ${ }^{21}$, luego de un período de alrededor de quince a veinte años con un programa de control similar al que se realiza en la XII Región.

La provincia de Ult. Esperanza es la que posee el mayor porcentaje de muestras positivas a la prueba de arecolina $(2,9 \% ; 3 / 103)$, seguida por T. del Fuego $(1,2 \%$; 1/85), mientras que la provincia de Magallanes no presenta muestras positivas con el mencionado test. Las prevalencias provinciales se mantienen relativamente constantes desde el muestreo del año 1982, Ult. Esperanza continua con la más alta prevalencia y aumenta porcentualmente, a diferencia de

José Leal, Med.Vet. Enc, Reg. Pecuario SAG, XII Región Av Bulnes 0309, Pta Arenas, Chile.Comunicación Personal 
Magallanes la cual disminuye a niveles no detectables. Este fenómeno requiere un estudio más acabado, en relación a los factores de riesgo, que por lo visto perduran través del tiempo, y afectan de diferente forma a las diversas Provincias, un ejemplo de esta situación puede ser la diferente cobertura de dosificación antiparasitaria canina, debido a mayor cantidad de lugares inaccesibles, catástrofes naturales y emergencias sanitarias eventuales.

Solo dos categorías etareas, la $\geq 3<5$ años $(4,8 \%)$ y $1 \mathrm{a} \geq 5$ años $(1,2 \%)$, presentaron muestras positivas mediante la prueba de la arecolina. De acuerdo a esta distribución se puede presumir que los animales más viejos tienen mayor probabilidad de infección con E. granulosus, debido a la mayor cantidad de tiempo que están expuestos a factores de riesgo, dejando en claro que no se puede realizar un estudio de riesgo con tan poca cantidad de datos.

En la Tabla 1, se observa que los perros que realizan sus trabajos en actividades ganaderas mixtas, presentan el mayor porcentaje de muestras positivas a la prueba de arecolina $(6,3 \%)$. No presentando muestras positivas los perros que trabajan exclusivamente con bovinos ni tampoco a los que se les tiene como mascotas. Esta situación, a diferencia del muestreo realizado el año 1982, en el cual los perros que trabajaban exclusivamente con ovinos representaron el mayor porcentaje de muestras positivas ${ }^{18}$, puede deberse a una discriminación en la entrega de educación sanitaria, la cual por factores de riesgo se centró en los propietarios que manejaban exclusivamente perros ovejeros.

En la Tabla 2 se observa que los predios con el mayor porcentaje de muestras positivas fueron las explotaciones ovinas $(14,3 \%)$, mientras que los predios bovinos no presentaron muestras positivas. Los resultados obtenidos en el presente trabajo se asemejan a los del estudio realizado en la XI Región en $1989^{22}$, aunque varían los valores porcentuales, coinciden en que los predios ovinos tienen mayor porcentaje de equinococosis, seguido de los predios mixtos.

Otro resultado interesante señalar es que también la provincia de Ult. Esperanza fue la que presentó el mayor porcentaje de predios con muestras positivas $(10,5 \% ; 2 / 19)$, mientras que T. del Fuego sólo presenta un 6,7\% (1/15) y Magallanes no posee predios con muestras positivas a la prueba de arecolina. A pesar de que
Tabla 1. Distribución de muestras fecales positivas al test de arecolina en relación al total de muestras según la actividad ganadera que realiza el perro. XII Región, Chile, 2002

\begin{tabular}{lcrr}
\hline Actividad & $\begin{array}{c}\mathbf{N}^{\circ} \text { muestras } \\
\text { positivas }\end{array}$ & $\%$ & $\begin{array}{r}\text { Total de } \\
\text { muestras }\end{array}$ \\
\hline Mixto & 2 & 6,3 & 32 \\
Ovinos & 2 & 1,7 & 115 \\
Bovinos & 0 & 0 & 8 \\
Mascota & 0 & 0 & 3 \\
Total & 4 & 1,8 & 228 \\
\hline
\end{tabular}

Fuente: SAG.

Tabla 2. Distribución de predios con muestras fecales caninas positivas al test de arecolina según explotación ganadera. XII Región, Chile, 2002

\begin{tabular}{|c|c|c|c|}
\hline \multicolumn{2}{|c|}{$\begin{array}{c}\text { Actividad } \mathbf{N}^{\circ} \text { predios con } \\
\text { muestras } \\
\text { positivas }\end{array}$} & $\%$ & $\begin{array}{r}\text { Total de predios } \\
\text { muestreados }\end{array}$ \\
\hline Ovinos & 2 & 14,3 & 14 \\
\hline Mixto & 1 & 5,6 & 18 \\
\hline Bovinos & 0 & 0 & 18 \\
\hline Total & 3 & 6,0 & 50 \\
\hline
\end{tabular}

Fuente: SAG.

sólo se dispone de datos parciales de algunas provincias, en años anteriores, se puede establecer que en general la equinococosis se ha mantenido en un número reducido de predios, debido principalmente a las labores constantes de vigilancia predial, educación sanitaria y tratamiento antiparasitario.

De acuerdo a lo obtenido en el presente trabajo se puede concluir que la prevalencia de equinococosis canina, en perros rurales de la XII Región, se mantiene en niveles bajos desde el año 1982, por lo que se debieran incrementar los esfuerzos en el Programa de Control y / o adoptar nuevas estrategias que permitan disminuir de manera eficaz la prevalencia de la enfermedad.

\section{RESUMEN}

El objetivo de este estudio fue estimar la prevalencia de equinococosis canina en la XII Región para el año 2001.Se diseñó un muestreo aleatorio el que incluyó 228 perros distribuidos en las tres Provincias en donde se desarrolla el 
Proyecto de Control de la Hidatidosis. A nivel de terreno se efectuó la prueba de arecolina y paralelamente se aplicó un cuestionario a los propietarios de perros. Se encontraron sólo cuatro perros positivos $(1,8 \%)$; tres en la Provincia de Última Esperanza y uno en Tierra del Fuego. Como conclusión se destaca que la prevalencia de equinococosis canina en la XII Región se mantiene en niveles bajos desde el año 1982, por lo que se debieran incrementar los esfuerzos para el control y / o adoptar nuevas estrategias que permitan disminuir de manera eficaz la prevalencia de la enfermedad.

\section{REFERENCIAS}

1.- THAKUR A. La distribución geográfica y algunos aspectos epidemiológicos de la hidatidosis en las Américas. En actas: VI Jornadas Nacionales de Hidatología, Córdoba, Argentina. 1976.

2.- GONZÁLEZ J, GONZÁLEZ G, SBAFFO A, et al. Equinococosis canina en un sector del Departamento de Río Cuarto, Provincia de Córdoba, Argentina. Arch Med Vet 1998; 30: 157-63.

3.- JAMES J, BENNETT P, BENNET I L. Céstodos o Tenias. En: Harrison Medicina Interna $4^{a}$ Ed. La Prensa Médica Mexicana, México Distrito Federal 1973; 1197-201.

4.- IVEY M H. Helmintos. En: Alex C. Sonnenwirth, Leonard Jarett Eds. Métodos y diagnósticos del laboratorio clínico. Panamericana $8^{\mathrm{a}}$ ed., Argentina; 1986; 98: 1962 - 1964. Original no consultado disponible en: SÁNCHEZ - GONZÁLEZ, J. 1997. Anticuerpos anti - Echinococcus (hidatidosis) mediante hemaglutinación pasiva, en sujetos expuestos a riesgo. Patol Clín México 1997; 44: 233-9.

5.- PAWLOWSKI J, ECKERT, D A, VUITTON R W, et al. Echinococcosis in humans: clinical aspect, diagnosis and treatment. In WHO/OIE Manual on Echinococcosis in Humans and Animal: a Public Health Problem of Global Concern. Eckert, J.; Gemmell, M. A.; Meslin, F. X.; Pawlowski, Z. S. eds. 20 - 71. 2001.

6.- OIE. OFICINA INTERNACIONAL DE EPIZOOTIAS. Chile / Equinococosis / hydatidosis. Multiannual Animal Disease Status. Handistatus II. 2002. Disponible en: http://www.oie.int.

7.- CHILE. MINISTERIO DE AGRICULTURA, SERVICIO AGRÍCOLA Y GANADERO. Vigilancia Epidemiológica. Boletín N 35.76 p. 1998.

8.- CHILE. Ministerio de Salud. Boletín Electrónico de Vigilancia en Salud Pública. Situación del carbunco, brucelosis, triquinosis, hidatidosis y enfermedad .de Chagas. 2002. Disponible en: http://epi.minsal.cl/evigia/Numero07/pag27.htm.

9. CASANOVA S M. Farmacognosia con Farmacodinamia. Ed Científico Médica Barcelona, España1968; 759- 61.

10.- OIE OFICINA INTERNACIONAL DE EPIZOOTIAS. Manual of standards for diagnostic tests and vaccines. $4^{\text {th }}$ ed., 2000. Disponible en: http://www.oie.int/eng/
normes/mmanual/A_00040.htm. Consultado el 24/09/ 2002.

11.- CABRERA P. Diagnóstico de Hidatidosis. Conferencia electrónica INTA, Argentina. 2001. Disponible en: http://www.inta.gov.ar/producto/helminto/ conf_stabile.htm.

12.- SCHANTZ P M. Sources and uses of survaillance data for cystic echinococcosis. In: Compendium on echinococcosis in Africa and in Middle Eastern Countries with special reference to Morocco. F. L. Andersen, H. Ouhelli, M. Kachani, eds. Bringham Young University Print Service, Provo, Utha. 1997; 72-84.

13.- CRAIG P S, GASSER R B, PARADA L, et al . Diagnosis of canine equinococosis : comparison of coproantigen and serum antibody tests with arecoline purgation in Uruguay. Vet Parasitol 1995; 56: 293-301.

14.- CHILE. Ministerio de Agricultura, Servicio Agrícola y Ganadero. M. Vidal; C. Bonilla; E. Jeria. Enfoque epidemiológico de los programas de Control de la Hidatidosis. XI y XII Región de Chile. 1992.

15.- CHILE, Ministerio de Agricultura, Servicio Agrícola y Ganadero, Ministerio de Salud XII Región, Representación OPS/OMS en Chile. Análisis epidemiológico de la estrategia aplicada. En: Proyecto Control Hidatidosis, XII Región. I Seminario Internacional de Hidatidosis, 14 - 15 Noviembre de 1988, Punta Arenas. 17 - 38.

16.- ALVAREZ J F. Prevalencia de coproantígenos a Echinococcus granulosus en fecas de perros en sectores urbanos, Puerto Natales, XII Región, Chile. XII Congreso Chileno de Medicina Veterinaria, 24 - 26 / 10/2002. Chillán, Chile. 2002.

17.- SCHANTZ P M. Guía para el empleo del bromhidrato de arecolina en el diagnóstico de la infección por Echinococcus granulosus en el perro. Bol Chil Parasitol 1973; 28: 81-90.

18.- PFEIFFER D U. Veterinary Epidemiology - An introduction. Epidemiology Division Department of Veterinary Clinical Sciences, The Royal Veterinary College, University of London. 2002. Disponible en: www.vetschools.co.uk/EpiVetNet/ epidivision/Pfeiffer/files/Epinotes.pdf.

19.- CHILE, MINISTERIO DE AGRICULTURA, SERVICIO AGRÍCOLA Y GANADERO. Evaluación Proyecto Control Hidatidosis XII Región. Período Septiembre 1979 a Diciembre 1982, Santiago, Chile. 69 p. 1983.

20.- CANTONI G, COSTA M, LABANCHI J, et al. Control Program of hydatid disease in the province of Rio Negro, Argentina 1980 / 1998. Arch Int Hidatid 1999; 33: 99-102.

21.- ZANINI F, BITSCH A. Perspectivas de erradicación de la hidatidosis en Tierra del Fuego, Argentina. Arch Int Hidatid 1999; 33: 19-23.

22.- CHILE. MINISTERIO DE AGRICULTURA, SERVICIO AGRÍCOLA Y GANADERO. Análisis por línea de acción del proyecto control de la hidatidosis 1982 - 1989. Bonilla, C.; Vidal, M. Chacón, S. 102 p. 1990.

Agradecimientos: A todos los colegas y Técnicos del Servicio Agrícola y Ganadero de la XII Región, por su cooperación en la realización del trabajo a nivel de terreno, destacando además su abnegada labor, durante más de veinte años, en el control de la hidatidosis en el sector rural. 